\title{
EL AGOTAMIENTO DE LA EXTENSIÓN PREVISTA COMO CAUSA DE FINALIZACIÓN DE LAS PRESTACIONES POR INCAPACIDAD TEMPORAL
}

\author{
José Luis LAFuente SuÁREZ \\ Abogado. Doctor en Derecho \\ por la Universidad de Oviedo \\ Licenciado en Ciencias del Trabajo \\ Profesor del Master de la Abogacía \\ Universidad de Oviedo \\ lafuente-buenaposada@logiccontrol.es
}

\begin{abstract}
RESUMEN
La extensión de la duración de la incapacidad temporal ba sido uno de los temas más modificados dentro de la normativa reguladora de una contingencia protegida en el sistema de la Seguridad Social española. Sigue generando además múltiples controversias, como muestra la regulación actual contenida en el Texto Refundido de la Ley General de la Seguridad Social de 2015, que contempla la combinación de las distintas opciones que las entidades gestoras y las mutuas ban de tomar en relación con las extensiones temporales posibles de esta contingencia protegida. A partir de ellas, mostramos la necesidad de justificar que el mero transcurso del tiempo no ha de ser entendido por sí mismo como causa de finalización de las prestaciones de incapacidad temporal, sino que debe conectarse con alguna de las circunstancias que la ley recoge como operadora de la extinción de la protección a través de esta contingencia.
\end{abstract}

Palabras clave: Servicio Público de Salud, Seguridad Social, incapacidad temporal, prestaciones, plazo.

\section{ABSTRACT}

The extension of the length of temporary inability - bereinafter temporary inability- has been one of the subjects with the most amendments within the legal system regulations for a contingency which is legally protected in the Spanish System of Social security. It continues to raise controversy as it is shown by the current wording of the amended text of the Social Security Act 2015, which studies the combination of the several options that managing entities and Mutual Insurance Companies have to choose regarding the likely temporary extensions of that provided contingency. It is through them that we can show the need to justify that the mere lapse of time should not be understood on its own as the reason to terminate temporary inability benefits, but it should also be connected with some of the circumstances the law welcomes as to terminate the protection through this contingency.

Keywords: NHS, Social Security, Temporary Inability, benefits, Deadline. 


\section{ZUSSAMENFASSUNG}

Die Verlängerung der Laufzeitfristen der kurzzeitlichen Arbeitsunfähigkeit —im folgenden abgekürzt durch kAU-ist eines der Themen die innerbalb der geltenden Vorschriften zu Leistungsarten der Spanischen Sozialversicherung am meisten abgeändert wurden. Außerdem verursacht sie verschiedenartige Kontroversen, wie die derzeitigen Vorschriften beweisen, die in der konsolidierten Fassung des allgemeinen Sozialrechts der Spanischen Sozialversicherung von 2015 enthalten sind. Diese sehen die Kombination von verschiedenen Optionen vor, welche die Ausführungsorgane und die Versicherungsgesellschaften ergreifen sollen bei möglichen zeitlichen Verlängerungen dieser Leistungsart. Ausgehend von diesen, verweisen wir auf die Notwendigkeit der Rechtfertigung des Umstands, so dass der bloße Umstand des verlängerten Zeitverlaufs nicht automatisch zur Beendigung der Leistungen der kAU fübren muss, sondern verbunden werden muss, mit einem der Umstände, die das Gesetz als Ausführungsorgan der Beendigung des Versicherungsschutzes für den Eventualfall beinhaltet.

Schlüsselwörter: staatliches Gesundheitswesen, Sozialversicherung, kurzzeitliche Arbeitsunfähigkeit, Sozialleistungen, Frist.

SUMARIO: I. INTRODUCCIÓN.-II. EL AGOTAMIENTO DEL PLAZO DE DURACIÓN DE LA IT.-III. PROCEDIMIENTO DE IMPUGNACIÓN EN VÍA ADMINISTRATIVA.- 1 . Agotamiento del plazo de 365 días en caso de contingencia común.- 2. Agotamiento de plazo de 365 días en caso de contingencias profesionales.-3. Acordada la prórroga del proceso de IT por 180 días más y cumplidos, por tanto, 545 días desde el inicio de la IT.- 4. Finalizado el plazo máximo de duración de la IT de 730 días.-IV. UN SUPUESTO A DIFERENCIAR: LA ANULACIÓN POR EL INSS DE BAJA MÉDICA EXPEDIDA POR EL MÉDICO DE ATENCIÓN PRIMARIA DEL SERVICIO PÚBLICO DE SALUD TRAS ALTA EMITIDA POR AQUÉL AL HABER TRANSCURRIDO MÁS DE 365 DÍAS DESDE EL INICIO DE UNA SITUACIÓN DE IT-V. EL ENJUICIAMIENTO DE LAS ALTAS MÉDICAS DE IT.- 1. La impugnación judicial de las altas médicas.- 2. La revisión judicial de la anulación de la baja médica por el INSS tras alta médica emitida transcurridos 365 desde el inicio de un proceso de IT.-VI. CONCLUSIONES.

\section{INTRODUCCIÓN}

Si bien las prestaciones de incapacidad temporal (en adelante, IT) abarcan la asistencia sanitaria y el subsidio económico, con carácter general al referirse a la finalización o extinción de la IT se está hablando de este último, esto es, de las prestaciones económicas, dado que el derecho a la asistencia sanitaria para un trabajador nace de su calidad de tal $^{1}$, aun cuando el empresario haya incumplido los deberes de afiliación y alta, por mor del principio de automaticidad de las prestaciones ${ }^{2}$, por lo que se mantiene en tanto en

${ }^{1}$ De acuerdo con el art. 2.1.a) del RD 1192/2012, de 3 de agosto.

2 Al entenderse de aplicación, con carácter reglamentario, los arts. 94 a 96 de la Ley 
cuanto el trabajador precise recibir los tratamientos correspondientes y concurran los requisitos necesarios para la conservación de este derecho ${ }^{3}$.

De este modo los arts. 169 y ss. del Texto Refundido de la Ley General de la Seguridad Social, aprobado por el Real Decreto Legislativo 8/2015, de 30 de octubre (en adelante, TRLGSS/2015), actualmente vigente, dentro del capítulo V del título I encabezado como «Incapacidad temporal», se refieren expresamente al «nacimiento y duración del derecho al subsidio» (art. 173) y extinción (art. 174). Por lo que hace al objeto de nuestro estudio, la finalización de la prestación económica de IT por agotamiento de su duración, estos dos artículos han de ponerse en relación con el 169, que da el concepto de las situaciones determinantes de la IT en función de su extensión temporal, y con el 170, que regula las competencias administrativas, igualmente en relación con el tiempo de extensión de la IT. Y ello, como analizaremos a continuación, porque el simple transcurso del tiempo de duración legalmente fijado de la IT, ya sea inicial o en virtud de prórrogas, no determina ex lege, ineludiblemente, la finalización de la protección económica a través del subsidio, tesis que defendemos en el presente trabajo $^{4}$. Dicho en términos de carácter administrativo de la Seguridad Social: el agotamiento de la extensión temporal de la IT no produce de forma automática el «alta» del trabajador y la extinción de la prestación económica si no está sustentada por una de las causas de extinción que la Ley señala.

\section{EL AGOTAMIENTO DEL PLAZO DE DURACIÓN DE LA IT}

El tema a debatir se encuentra, pues, directamente relacionado con el trámite correspondiente al agotamiento del plazo de duración de la IT

General de la Seguridad Social de 1966, texto articulado I, aprobado por Decreto 907/1966, de 21 de abril.

${ }^{3}$ Conforme a los arts. 6 y 7.1.2.a) del precitado RD 1192/2012.

${ }^{4}$ En relación con la anterior Ley de Procedimiento Laboral, que permitía el recurso de suplicación en los procesos de impugnación de altas médicas, la Sentencia de la Sala de lo Social del TSJ de Asturias de 18 de octubre de 2010, dictada en el recurso núm. 1790/2010, afirmaba: «De las opciones restantes, la más conforme con el cuadro morboso del demandante es la que dispone el alta médica para el inicio de un expediente de incapacidad permanente, toda vez que la sentencia de instancia considera definitiva la situación patológica y ésta es también la opinión del trabajador». En el mismo sentido vid. las Sentencia del Juzgado de lo Social núm. 1 de Oviedo, de 22 de abril de 2014 (dictada en autos 321/14); del Juzgado de lo Social núm. 3 de Oviedo, de 25 de agosto de 2015 (dictada en autos 480/2015), y del Juzgado de lo Social núm. 5 de Oviedo, de 30 de junio de 2016 (dictada en autos 404/2016 B), si bien referida a un trabajador autónomo. 
que el TRLGSS/2015 viene a fijar, con carácter sucesivo, en su caso, en los artículos citados en función de la contingencia causante, pero a estos efectos solamente distinguiendo, de una parte, entre contingencias comunes y profesionales, $\mathrm{y}$, de otra, los periodos de observación por enfermedad profesional, ya que ésta es la diferencia relativa a la duración que contempla el concepto extensivo ofertado por el referido art. 169 del TRLGSS/2015 de las causas productoras de la IT.

Sobre esta base distinguiremos los supuestos que se pueden presentar en relación con la duración sucesivamente fijada en la norma de Seguridad Social. Así:

1. En los casos de IT derivados de contingencias comunes o profesionales, transcurridos 365 días desde el inicio de la contingencia cubierta, la Dirección Provincial correspondiente del Instituto Nacional de la Seguridad Social (en adelante, INSS), tras dictamen del Equipo de Valoración de Incapacidades (en adelante, EVI), y, por consiguiente, previo y necesario examen médico del trabajador, será el órgano competente para decidir ex art. 170.2 del TRLGSS/2015:

1.1. Si procede una prórroga de la situación de IT por otros 180 días más, durante los cuales se prevea la curación del trabajador:

- El inicio de un expediente de Incapacidad Permanente, por entender que las lesiones o padecimientos del trabajador suponen su encuadramiento en las definiciones del artículo.

- El alta del trabajador por encontrarse restablecido, por lo que procede su reincorporación al trabajo.

Para cualquiera de las decisiones a adoptar por el INSS 5 será conditio sine qua non el previo examen médico del trabajador en situación de baja.

1.2. Decidida la prórroga por 180 días más, al finalizar ésta, es decir, al haberse extendido la IT 545 días de acuerdo con el art. 174.2 TRLGS/2015, procede el reconocimiento médico del trabajador por parte del EVI, y la Dirección Provincial del INSS competente ha de decidir en el plazo máximo de tres meses si procede la calificación del trabajador en alguno de los grados de Incapacidad Permanente o, en sentido diferente,

${ }^{5}$ Nos estamos refiriendo a las causas de extinción relacionadas con el estado físico/psíquico del trabajador, esto es, con independencia de las otras causas de extinción de la prestación de IT que regula el art. 174 del TRLGSS/2015: incomparecencia injustificada a los exámenes y reconocimientos médicos prescritos, jubilación, alta sin declaración de incapacidad o fallecimiento. 
si se ha producido la curación o mejoría del trabajador que conducirá a la emisión del parte de alta, con la excepción que a continuación estudiaremos. De esta forma, en paralelo con el supuesto analizado anteriormente, el transcurso del plazo de 545 días no supone la necesaria extinción de la prestación económica de IT, sino la propuesta del EVI y la decisión del INSS acerca de la realidad de una Incapacidad Permanente del trabajador o, en su caso, la extensión del alta por su curación o mejoría que permite la vuelta al trabajo.

1.3. Otro supuesto más, diferente de los anteriores, se produciría ex art. 174.2, párrafo segundo, del TRLGSS/2015 cuando, transcurridos los precitados 545 días desde el inicio de la IT, la necesidad de continuación del tratamiento médico del trabajador generase la expectativa de su curación o mejoría que le permitiese reincorporarse efectivamente al trabajo. En este caso, se prolongaría la situación de IT con el retraso en la calificación de la situación del trabajador por el periodo que se estimase preciso para la curación o mejoría (hasta 180 días más), pero, en todo caso, sin exceder tal prolongación de un máximo de 730 días desde el inicio de la IT, de forma que tal extensión constituye la duración límite de esta contingencia protegida.

En paralelo con las situaciones anteriores, desde la perspectiva de estudio que hemos adoptado, la única posibilidad diferente del reconocimiento de una Incapacidad Permanente sería la emisión del alta del trabajador por curación o mejoría que permita la reanudación de su actividad laboral.

Para que la Dirección Provincial del INS competente adoptara la decisión de tal prolongación a la duración máxima de 730 días, al igual que en todos y cada uno de los supuestos anteriores, es necesario el previo examen médico del trabajador por parte del EVI y su propuesta en ese sentido que, normalmente, deberá ser aceptada por aquélla.

2. Para los casos en los que la IT derive del inicio de un periodo de observación, necesario para el diagnóstico de una enfermedad profesional, de acuerdo con el art. 169.1.b) del TRLGSS/2015, la extensión del mismo será de seis meses. Transcurrido ese plazo inicial, la Dirección Provincial del INSS, previo reconocimiento médico del trabajador a cargo del EVI, decidirá:

- Si se ha confirmado el diagnóstico de la enfermedad profesional que presuntamente podía padecer el trabajador, en cuyo caso éste pasaría a la situación de IT por padecimiento de una enfermedad profesional. 
- El inicio de un expediente de Incapacidad Permanente en caso de que la enfermedad profesional haya producido lesiones irreversibles, reducciones anatómicas o funcionales graves, susceptibles de determinación objetiva y previsiblemente definitivas que disminuyan o anulen su capacidad laboral, en los términos del art. 193 del TRLSS/2015.

- El alta del trabajador en esta situación al haberse descartado la existencia de una enfermedad profesional. Ello sin perjuicio de que el trabajador iniciase una situación distinta de IT derivada de contingencias comunes por los padecimientos sufridos por aquél que limiten su capacidad laboral.

- Una prórroga de seis meses por entenderse necesaria para el estudio y diagnóstico definitivo de la enfermedad profesional.

En este último caso, esto es, acordada la prórroga y llegado el final de la misma (y, por consiguiente, transcurridos como máximo doce meses desde el inicio del periodo de observación), la ley no prevé la existencia de una extensión de la IT derivada de la continuación del periodo de observación por enfermedad profesional, por lo que, como expresamos en el apartado inmediatamente anterior, la Dirección Provincial del INSS, previo reconocimiento médico del trabajador por el EVI, deberá decidir entre la confirmación del diagnóstico de padecimiento de la enfermedad profesional por el trabajador, que iniciaría una situación de IT derivada de contingencias profesionales; el alta médica del trabajador por no padecer la enfermedad profesional y estar capacitado para trabajar; el inicio de un expediente de incapacidad permanente, o el inicio, en su caso, de una nueva situación de IT derivada de contingencias comunes.

\section{PROCEDIMIENTO DE IMPUGNACIÓN EN VÍA ADMINISTRATIVA}

A partir de las consideraciones realizadas, estudiaremos el procedimiento de impugnación en vía administrativa de las resoluciones que se aparten del criterio que estimamos correcto y defendemos.

Agotado el periodo de duración inicial de 365 días de la prestación de IT, diferenciamos, a su vez, según la causa de la baja sea contingencia común o profesional. 


\section{Agotamiento del plazo de 365 días en caso de contingencia común}

\section{A. Manifestación de disconformidad}

Frente a la Resolución de la Dirección Provincial del INSS que decida la emisión del alta por curación o mejoría del trabajador que le permita reanudar su trabajo (puesto que, como mantenemos, no cabe la emisión del alta por el mero transcurso del tiempo), con la que éste no esté de acuerdo, cabe formular la manifestación de disconformidad con el alta en el plazo máximo de cuatro días naturales ${ }^{6}$, de acuerdo con el art. 170.2, párrafo segundo, del TRLGSS/2015. La manifestación de disconformidad se formula ante la Inspección Médica del Servicio de Salud autonómico competente, la cual puede discrepar con el alta formulada o confirmarla expresa o tácitamente ${ }^{7}$. Si la Inspección discrepara del criterio de la entidad gestora de emisión del alta, podrá proponer a ésta, en el plazo máximo de siete días naturales, la reconsideración de su decisión, «especificando las razones y fundamento de su discrepancia», indica el párrafo segundo in fine del mismo art. 170.2 del TRLGSS/2015.

En el supuesto de que, en virtud de la discrepancia formulada por el trabajador o de la propuesta de la Inspección Médica, la Dirección Provincial del INSS, previa consulta al EVI, reconsiderara su decisión, se reconocerá al interesado la prórroga de la situación de IT. En sentido contrario, si se reafirmara la entidad gestora en el alta, sólo se prorroga la situación de IT hasta la fecha de la última resolución confirmatoria del alta médica ${ }^{8}$.

Es de destacar que el texto expreso del párrafo cuarto del art. 170 del TRLGSS/2015 compulsa a la Dirección Provincial del INSS a aportar las

${ }^{6}$ El que el plazo sea tan breve y que la extensión de los partes de alta se produzca los viernes, como la experiencia práctica nos enseña, nos demuestra, de una parte, la poca importancia que el legislador concede a la manifestación de disconformidad y, de otra, la indefensión que suele provocar al trabajador, dado que ordinariamente se han perdido dos días (sábado y domingo) para la formulación de la impugnación.

${ }^{7}$ La confirmación tácita se produce por falta de pronunciamiento expreso en el plazo de los once días naturales siguientes a la fecha de la emisión del alta, según el párrafo tercero del núm. 2 del art. 170 del TRLGSS/2015.

${ }^{8} \mathrm{La}$ jurisprudencia del TS ha matizado que procede abonar el subsidio hasta el momento de la notificación de la resolución administrativa, sin que pueda perjudicar, en este caso al trabajador, la demora en la comunicación de aquélla. Vid. Sentencias de la Sala de lo Social del TS de 18 de enero de 2012 (recurso núm. 715/2011), y de 2 de diciembre de 2014 (recurso núm. 573/2014). 
pruebas complementarias (el destacado es nuestro) que fundamenten su decisión de confirmar el alta cuando haya existido propuesta de reconsideración por parte de la Inspección Médica, pero, ciertamente, la práctica nos indica que, de una parte, es escasísima la intervención de la Inspección Médica formulando propuestas de reconsideración de altas médicas emitidas por la entidad gestora, y, de otra, que las pruebas complementarias suelen limitarse a la emisión de un nuevo informe del EVI ratificando su anterior proposición.

La mera acreditación de la formulación de la disconformidad hace que la IT se vea prorrogada hasta que el alta médica adquiera plenos efectos, esto es, hasta el transcurso de once días naturales siguientes a su emisión, de acuerdo con el párrafo tercero del mismo art. 170.2 del TRLGSS/2015.

La manifestación de disconformidad, en fin, de acuerdo con el desarrollo reglamentario constituido por el RD 1430/2009, que en su art. 8.12 y los arts. 71 y 140 de la Ley 36/2011, de 10 de octubre, reguladora de la Jurisdicción Social (en adelante, LRJS), constituye realmente el cauce de agotamiento de la vía administrativa ${ }^{9}$, por lo que la resolución de la entidad gestora será impugnable directamente ante la jurisdicción social como estudiaremos.

\section{B. Formulación de reclamación previa}

Viene a constituir el supuesto de impugnación de alta médica que no haya seguido el cauce de la manifestación de disconformidad. Es decir, si frente al alta médica no se ha presentado una manifestación de disconformidad, cabe aún su impugnación a través de la vía ordinaria, esto es, agotando la vía administración mediante la interposición de una reclamación previa. A diferencia del supuesto anterior, la formulación de ésta no produce el efecto de extender la situación de IT en los once días siguientes.

En este caso, frente al alta médica puede formularse reclamación previa al amparo del párrafo segundo del núm. 2 del art. 71 LRJS en el plazo de once días hábiles desde la emisión y entrega del parte de alta. La entidad gestora deberá contestar en el plazo de siete días hábiles, transcurridos los cuales se entenderá desestimada la reclamación previa, según dispone el párrafo segundo del núm. 5 del mismo art. 71 LRJS.

9 Aunque el art. 140.1 LRJS recoge que en estos supuestos no será preciso el previo agotamiento de la vía administrativa, se está refiriendo a que no es necesaria la reclamación previa. 


\section{Agotamiento de plazo de 365 días en caso de contingencias profesionales}

Sobre la base de que la cobertura de dichas contingencias se ha formalizado con una mutua colaboradora con la Seguridad Social ${ }^{10}$, la emisión del parte de alta por ésta, con la que el trabajador discrepase, se producirá con carácter ordinario por curación del trabajador o mejoría que permite reanudar el trabajo ${ }^{11}$.

\section{A. Procedimiento especial de revisión}

Ante la emisión de ese alta médica, el trabajador puede iniciar el procedimiento administrativo especial de revisión de la misma de acuerdo con lo establecido en el art. 4 del RD 1430/2009. Para ello ha de presentar la solicitud de revisión ante la Dirección Provincial del INSS o el Instituto Social de la Marina (en adelante, ISM) mediante el impreso disponible en la página web de la entidad ${ }^{12}$ en el plazo de diez días hábiles siguientes a la recepción del alta médica, acompañando el historial médico relacionado con el proceso de IT o, en su caso, copia de la solicitud de dicho historial a la mutua colaboradora con la Seguridad Social. El INSS o, en su caso, el ISM comunicará a la mutua colaboradora el inicio del procedimiento especial de revisión para que aporte los antecedentes relacionados con el proceso de IT en el plazo improrrogable de cuatro días hábiles y a la empresa en el de dos días hábiles. A su vez, cuando el interesado solicite una baja médica derivada de contingencias comunes y se reconociera la existencia de un proceso previo de IT derivado de contingencia profesional en el que se hubiera emitido un alta médica, el Servicio de Salud deberá informar al interesado sobre la posibilidad de iniciar el procedimiento especial de revisión en el plazo de los diez días hábiles siguientes

${ }^{10}$ El concierto de cobertura de contingencias profesionales con el INSS sólo pueden mantenerlo las empresas que lo tuvieran antes de 1998.

${ }^{11}$ Se entiende que el alta con propuesta de incapacidad no sería impugnada por el trabajador. Cierto es que, de acuerdo con el art. 175.1.a) y 2 del TRLGSS/2015, cabrían el alta por actuación fraudulenta del trabajador para la obtención o conservación del trabajador por prestación de servicios por cuenta propia o ajena, por abandono o rechazo del tratamiento médico, pero éstos son supuestos de actuación anómala y, por tanto, precisarían una respuesta individualizada.

${ }^{12}$ www.seg-social.es. 
al de notificación del alta médica, comunicando además a la entidad gestora competente con carácter inmediato la existencia de dos procesos distintos de IT que pudieran estar relacionados. En estos casos se iniciará el abono de la prestación de IT por contingencias comunes hasta la resolución del procedimiento, sin perjuicio del reintegro por parte de la mutua a la entidad gestora en el caso de que el alta expedida por ella no produzca efecto y con el abono al interesado de la diferencia a su favor. La mutua podrá pronunciarse reconociendo la improcedencia del alta emitida, en cuyo caso se produce el archivo del expediente; en otro caso, el director provincial competente dictará la resolución que corresponda, previo informe preceptivo del EVI, en el plazo máximo de quince días hábiles desde la aportación de la documentación por parte de la entidad colaboradora, y contendrá, según el núm. 7 del art. 4 del RD 1430/2009, alguno de los siguientes pronunciamientos:

- Confirmación del alta médica emitida por la mutua colaboradora y declaración de la extinción del proceso de IT.

- Mantenimiento de la situación de IT derivada de contingencia profesional por considerar que el trabajador continúa con dolencias que le impiden trabajar.

- Determinación de la contingencia común o profesional de la que derive la IT cuando coincidan procesos intercurrentes en el mismo periodo de tiempo y, por tanto, existan distintas bajas médicas, fijando igualmente los efectos que correspondan en el proceso de IT como consecuencia de la determinación de la contingencia causante.

- Cuando el interesado hubiera recuperado la capacidad laboral durante la tramitación del procedimiento se podrá declarar sin efectos el alta médica por considerarla prematura, determinando la resolución la nueva fecha de efectos del alta médica y la consiguiente extinción del proceso de IT.

El inicio de este expediente, que ha de ser tramitado con carácter preferente por la entidad gestora, suspende los efectos del alta, manteniéndose prorrogada la situación de IT y, por consiguiente, también el abono de la prestación económica. Sin embargo, y a diferencia del procedimiento de disconformidad anteriormente visto, la resolución de la entidad gestora confirmando el alta daría lugar a la devolución por parte del trabajador de la prestación percibida durante ese periodo de suspensión al considerarse indebidamente percibida, según determina el núm. 8 del art. 4 del precitado RD 1430/2009. 
De acuerdo con el núm. 12 del art. 4 de este RD 1430/2009, la resolución del expediente de revisión de las altas médicas expedidas por las mutuas colaboradoras con la Seguridad Social tendrá los efectos atribuidos a la resolución de una reclamación previa de conformidad con lo dispuesto por el art. 71.6 párrafo segundo, de la LRJS, de forma que es directamente impugnable ante los Juzgado de lo Social.

\section{B. Reclamación previa frente a la mutua colaboradora}

De otra parte, frente a la emisión de alta ante la cual no se haya iniciado el procedimiento especial de revisión puede formularse reclamación previa ante la propia mutua colaboradora con la Seguridad Social, según el núm. 3 del art. 71 LRJS, en el plazo de once días hábiles desde la notificación del alta, de acuerdo con el párrafo segundo del núm. 2 del mismo art. 71. En este supuesto, la formulación de la reclamación previa no produce la prórroga referida en el apartado anterior de once días naturales.

La contestación a la misma ha de producirse en el plazo de siete días hábiles, entendiéndose desestimada una vez transcurrido el mismo al disponerlo así el párrafo segundo del núm. 5 del precitado art. 71 de la Ley Procesal. La desestimación, expresa o tácita, abre la vía jurisdiccional social.

\section{Acordada la prórroga del proceso de IT por $\mathbf{1 8 0}$ días más y cumplidos, por tanto, 545 días desde el inicio de la IT}

1. Como quiera que el órgano competente para la adopción de resolución en el proceso de IT transcurridos más de 365 días, es la Dirección Provincial del I. N. S. S., de acuerdo con el art. 170.2 TRLGSS/2015, agotados los 545 días naturales de duración de la IT, tanto en procesos derivados de contingencias comunes como profesionales, se revisará necesariamente en el plazo de tres meses el estado del trabajador por el E. V. I. y éste propondrá a la Dirección Provincial la decisión sobre el inicio de un expediente de Incapacidad o la emisión del alta médica por curación o mejoría que permite trabajar, pues en paralelo con lo defendido y argumentado anteriormente, el mero transcurso del tiempo no supone la extinción per se, de la cobertura de la prestación de IT sino que el alta ha de estar motivada por el concurso de alguna de las circunstancias recogidas en el art. 174.1 TRLGSS/2015. 
La resolución que acuerda el alta del trabajador transcurridos 545 días desde el inicio de la IT es impugnable por medio de reclamación previa formulada ante la entidad gestora en el plazo de once días laborables, a tenor de los núms. 1 y 2, párrafo segundo, del art. 71 LRJS, y la contestación ha de producirse dentro de los siete días siguientes a su interposición, y se entenderá desestimada con el transcurso de dicho plazo en virtud del párrafo segundo del núm. 5 del mismo artículo, lo que abre la vía judicial de su impugnación.

2. Una situación de excepción contempla el párrafo segundo del núm. 2 del art. 174 del TRLGSS/2015 al establecer un retraso en la calificación de la situación del trabajador hasta alcanzar un máximo de 730 días naturales desde el inicio de la IT en los casos en los que el trabajador continúa necesitando tratamiento médico y por la expectativa de su recuperación laboral se hiciera aconsejable demorar aquélla. Este retraso supondría la prórroga de la situación de IT que debe acordar expresamente la Dirección Provincial de la entidad gestora.

Para los supuestos de revisión en el plazo de tres meses y extensión hasta el máximo de 730 días naturales, el trabajador percibiría la prestación económica directamente de la entidad gestora y la empresa no tendría obligación de cotizar.

La emisión de alta médica por curación o mejoría que permite reanudar el trabajo dentro de ese plazo de tres meses es impugnable en los mismos términos descritos en el número anterior, esto es, interposición de reclamación previa en el plazo de once días laborales y contestación expresa o desestimación tácita por el transcurso de siete días laborables.

\section{Finalizado el plazo máximo de duración de la IT de 730 días}

En paralelo con lo expresado respecto al agotamiento de los periodos de 365 y 545 días referidos, la entidad gestora, previo reconocimiento médico por parte del EVI del trabajador en situación de IT, ha de resolver, de acuerdo con lo prevenido en el art. 174.1 del TRLGSS/2015, acordando el alta médica por curación o mejoría o el inicio de un expediente de Incapacidad Permanente del que se derivará el reconocimiento o no de tal situación ${ }^{13}$. La resolución motivada que acuerde el alta médica, de acuerdo

13 Insistimos, sin referirnos al resto de causas contempladas por el art. 174 del TRLGS/2015 no derivadas de la situación del trabajador, como son la jubilación, el fallecimiento o la incomparecencia a las revisiones médicas. 
con lo estudiado en los dos apartados anteriores, sería impugnable ante la entidad gestora en el plazo de once días laborables mediante reclamación previa, con desestimación tácita por silencio administrativo una vez transcurridos siete días laborables desde la formulación de aquélla.

\section{UN SUPUESTO A DIFERENCIAR: LA ANULACIÓN POR EL INSS DE BAJA MÉDICA EXPEDIDA POR EL MÉDICO DE ATENCIÓN PRIMARIA DEL SERVICIO PÚBLICO DE SALUD TRAS ALTA EMITIDA POR AQUÉL AL HABER TRANSCURRIDO MÁS DE 365 DÍAS DESDE EL INICIO DE UNA SITUACIÓN DE IT}

A este respecto entiendo que es necesario realizar una diferenciación entre los procesos de impugnación de alta médica hasta ahora estudiados y aquellos otros en los que se produce la emisión de una baja médica por el médico de familia o de atención primaria perteneciente al Servicio Público de Salud, y, posteriormente, no un alta, sino que dicha baja médica es anulada por la Dirección Provincial del INSS en alegación de la facultad exclusiva que le corresponde, de acuerdo con el núm. 2 del art. 170 del TRLGSS/2015, de emitir una nueva baja médica, por la misma o similar patología, dentro de los 180 días siguientes a la emisión de alta médica, tras al agotamiento del plazo inicial máximo de 365 días de prestación de IT.

En estos supuestos ya no nos encontramos ante una impugnación de alta médica, sino que la anulación de la emisión de la baja médica, y, por tanto, su no producción de efectos, constituye una denegación de prestaciones de Seguridad Social (en este caso de IT), por lo que su trámite administrativo ha de seguir el cauce de la reclamación previa ordinaria previsto en el art. 71.1 y 2 LRJS, que se formulará en el plazo de treinta días hábiles contados a partir de la notificación de la anulación de la baja. Su desestimación expresa o tácita por silencio administrativo al transcurrir cuarenta y cinco días hábiles desde la interposición de aquélla, como prescribe el núm. 5 del mismo artículo, será recurrible ante la jurisdicción social en el plazo de treinta días hábiles contados desde la fecha en que se notifique la denegación de la reclamación previa o desde el día en que se entienda denegada tácitamente (núm. 6 del mismo art. 71 LRJS). El procedimiento ante la jurisdicción social será, por tanto, no el previsto para la impugnación de altas, sino el ordinario de Seguridad Social. 


\section{EL ENJUICIAMIENTO DE LAS ALTAS MÉDICAS DE IT}

\section{La impugnación judicial de las altas médicas}

Terminada la vía administrativa, ya sea por la formulación de la manifestación de disconformidad, por el procedimiento especial de revisión de altas médicas o por la presentación de reclamación previa, según hemos estudiado, tales altas o resoluciones confirmatorias de las mismas, según el caso, son impugnables en vía jurisdiccional social de acuerdo con el art. 2.o) LRJS, que se refiere a la competencia de los órganos de esta jurisdicción en materia de prestaciones de Seguridad Social, estableciendo el núm. 3 del art. 140 las peculiaridades de las reclamaciones frente a las altas médicas.

De este modo, es de señalar que, de acuerdo con la combinación de los párrafos primero y segundo del núm. 6 del art. 71 LRJS, la demanda ha de formularse en el plazo de veinte días hábiles desde la resolución expresa confirmatoria del alta o la adquisición plena de efectos de la misma (supuesto 1.1), de la desestimación expresa de la reclamación previa (supuestos 1.2, 2, 3 y 4) o desde la desestimación tácita de la referida reclamación previa (igualmente supuestos 1.2, 2, 3 y 4).

En cuanto al procedimiento, el art. 140 lo califica de urgente, de tramitación preferente, en el que la demanda se ha de dirigir exclusivamente contra la entidad gestora o la mutua colaboradora con la Seguridad Social, sin que sea preciso codemandar al Servicio Público de Salud, salvo que el alta hubiera sido emitida por éste, ni tampoco a la empresa, salvo que se cuestione la contingencia. A la impugnación del alta no podrán acumularse otras acciones, ni siquiera de reclamación de diferencias en la prestación económica, si bien, de estimarse la demanda por considerar indebida el alta, dispondrá la reposición al beneficiario en la prestación que hubiere venido percibiendo en tanto no concurra causa de extinción.

La sentencia resolverá exclusivamente sobre los efectos del alta impugnada, de forma que la prueba ha de versar en general, desde la perspectiva del demandante, sobre la situación del actor que:

- bien no está restablecido pero, por presumirse que su curación se ha de producir dentro de los límites temporales que la contingencia protegida de IT cubre, ha de continuar en IT hasta su restablecimiento (prórroga, demora en la calificación);

- bien porque se encuentra en una situación encuadrable en el concepto de incapacidad permanente por presentar (ex art. 193 del 
TRLGSS/2015) reducciones anatómicas o funcionales graves, susceptibles de determinación objetiva, previsiblemente definitivas, que disminuyan o anulen su capacidad laboral, por lo que ha de iniciarse un procedimiento de Incapacidad Permanente.

Y desde el punto de vista de la entidad gestora o de la mutua colaboradora, debe probar que la situación del demandante es susceptible de producir su vuelta al trabajo habitual.

De este modo, son las pruebas documentales (informes médicos) y periciales (comparecencia de médicos que han atendido al demandante, tratándose de mutuas colaboradoras, o médicos especialistas actuando como perito de parte) las que van a servir de soporte a la decisión judicial ad hoc. Ciertamente, la lógica nos indica que, aun cuando se defina la decisión sobre la incapacidad en general - y en el supuesto que estudiamos, la incapacidad temporal - como una cuestión técnico-jurídica, lo cierto es que el fundamento de aquélla es la opinión o criterio médico. A este respecto, entiendo que sería lo ideal para el juzgador contar con la intervención como testigo-perito (ex art. 370.4 LEC) del médico especialista que habitualmente esté tratando al trabajador, que, con carácter general, estará prestando sus servicios en un centro hospitalario y para un servicio público integrado en el Sistema Público de Salud, de forma que la petición aceptada por el juzgado de su citación se pudiera llevar a cabo con la debida antelación para permitir, en paralelo, la organización de su trabajo y evitar de ese modo que su ausencia pudiera causar perjuicios a sus pacientes. Pero la práctica forense nos muestra que, como se apuntaba críticamente, los Juzgados de lo Social suelen rechazar la petición, por lo que la intervención del testigo-perito viene a darse por un favor personal del médico al acudir voluntariamente a la vista oral en el Juzgado de lo Social como favor personal a su paciente-trabajador ${ }^{14}$.

${ }^{14}$ Permítaseme la falta de modestia al citar la opinión crítica al respecto expresada en mi tesis doctoral «La incapacidad temporal en el Régimen General de la Seguridad Social», codirigida por Joaquín García Murcia y María Antonia Castro Argüelles, defendida el 22 de julio de 2016 en la Universidad de Oviedo ante el Tribunal compuesto por María de los Reyes Martínez Barroso (presidenta), María Antonia Pérez Alonso e Iván Antonio Rodríguez Cardo (vid. pp. 290 y ss.). En ella se recoge la redacción expresa de un Auto de 8 de marzo de 2007 de un Juzgado de lo Social asturiano que desestima el recurso de reposición interpuesto frente a providencia que rechazaba la petición de citación de un médico de un hospital público como perito-testigo para decir: «Por lo que de accederse a tal pretensión, los centros públicos hospitalarios y asistenciales quedarían prácticamente vacíos si tuviesen que acudir a testificar en relación con sus pacientes en los múltiples juicios que por tales cuestiones se solventan diariamente en este jurisdicción». 
Tal vez puedan apuntarse dos soluciones paralelas: de una parte, la intervención personal del especialista podría verse obviada con la emisión de informes más claros e inteligibles, incluyendo la opinión del profesional respecto a la aptitud laboral del paciente. Decimos opinión puesto que, de acuerdo con el expresado carácter técnico-jurídico del concepto de incapacidad, los jueces de lo social se muestran sumamente celosos de su propia competencia decisoria, que no dejaría por ello de serlo para estar fundada más sólidamente. De otra, la intervención del médico forense, contemplada por el art. 93.2 LRJS como una facultad del juez de lo social, de oficio o a instancia de parte, al tener una consideración valorativa más independiente, pues no olvidemos que las pruebas documentales y periciales médicas presentadas por las entidades gestoras o mutuas colaboradoras con la Seguridad Social, en su caso, no dejan de ser prueba de parte ${ }^{15}$.

La sentencia, en fin, de este proceso de impugnación de alta médica no tiene recurso por imperativo expreso de los arts. 140.3.c) y 190.1.g) LRJS, cualquiera que fuese la cuantía de la prestación económica que el trabajador hubiera venido percibiendo.

\section{La revisión judicial de la anulación de la baja médica por el INSS tras alta médica emitida transcurridos 365 días desde el inicio de un proceso de IT}

Este supuesto, como hemos visto en la impugnación administrativa, no supone la existencia de un alta médica, sino una anulación de la baja emitida por el médico del Servicio Público de Salud; anulación resuelta por la Dirección Provincial del INSS competente por tratarse de una nueva baja producida tras el alta, emitida, a su vez, por este último órgano, al haber transcurrido más de 365 días desde el inicio del proceso de IT a que puso término el alta. De ahí que el procedimiento ante la jurisdicción social será no el previsto para la impugnación de altas, sino el ordinario de prestaciones de Seguridad Social, y la sentencia podrá ser objeto de recurso de suplicación a tenor del art. 191.3.c) LRJS, al tratarse de un proceso que versa sobre reconocimiento o denegación del derecho a obtener prestaciones de Seguridad Social ${ }^{16}$. Pero para ello es importante que tanto el demandante

15 Me remito a la nota anterior. Vid. pp. 293 y 294 de mi tesis.

16 Sentencia de la Sala de lo Social del TSJ de Asturias de 13 de noviembre de 2015, dictada en el recurso de suplicación núm. 2217/2015. 
como los juzgadores diferencien claramente este tipo de procedimientos y se evite la confusión con los de impugnación de alta médica ${ }^{17}$.

\section{CONCLUSIONES}

Del análisis de los supuestos que hemos estudiado podemos extraer las siguientes y breves conclusiones:

Primera. El mero transcurso de los plazos legalmente establecidos sobre la prestación de IT no conlleva necesariamente el alta médica. Ésta ha de venir producida por la conexión entre el cumplimiento de los sucesivos plazos de duración de la IT (365, 545 y 730 días, respectivamente, para la contingencia protegida de IT derivada de contingencias comunes o profesionales; seis o doce meses en los periodos de observación por enfermedad profesional) y alguna de las otras causas de extinción de la prestación.

Segunda. El objeto de la prueba está limitado a la valoración de la situación del trabajador; decisión técnico-jurídica adoptada por el juzgador pero que precisaría un apoyo imparcial de su decisión, bien a través de un correcto enfoque de la prueba documental médica de testigo-perito del médico especialista que atienda al trabajador en situación de IT, bien, en su caso, por el soporte del dictamen del médico forense, puesto que los informes médicos derivados de EVI perteneciente al INSS o, en su caso, a la mutua colaboradora con la Seguridad Social, no dejan de tratarse de informes a instancia de una Administración Pública que no deja de ser parte interesada en el proceso, al ser entes pagadores de las prestaciones económicas.

Tercera. Es preciso distinguir los supuestos de impugnación de alta médica de la anulación de bajas emitidas por el Servicio Público de Salud o por el INSS en virtud de la facultad que le corresponde merced al contenido de los arts. 170.2 y 174.1, párrafo tercero, del TRLGSS/2015, haciendo expresa referencia a ella en la demanda a interponer ante la jurisdicción social, puesto que se trata de un proceso de prestaciones de Seguridad Social basado en la denegación de las mismas (la anulación de la baja supone denegación de prestación económica) y no específicamente el especial de impugnación de altas médicas.

${ }_{17}$ Cfr. Sentencia de la Sala de lo Social del TSJ de Asturias de 18 de mayo de 2016, dictada en el recurso de suplicación núm. 833/2016, donde se inadmite el recurso por confundir la anulación de una baja médica con la emisión de un alta. 